\title{
Research on the Safety Monitoring Scheme for Old Building under Limited Funds
}

\author{
HUANG Xiaocai ${ }^{* 1,2}$, SHI Yuanfeng ${ }^{2}$, MAO Ling ${ }^{2}$, YANG Luyu ${ }^{2}$, WANG Mohan ${ }^{2}$ \\ ${ }^{1}$ WuYuZhang Honors College, Sichuan University, Chengdu, China \\ ${ }^{2}$ College of Architecture and Environment, Sichuan University, Chengdu, China
}

\begin{abstract}
The importance of ensuring the security of old buildings in unsatisfying and worrying safety state is definitely certain. As it is of high cost to implement comprehensive safety monitoring, it is necessary to establish an optimization model of old housing safety monitoring scheme combined with technology and economy. To obtain the relatively most efficient means of choosing specific schemes of the safety monitoring of old housing, analytic hierarchy process is selected, which is capable of reducing complexity.
\end{abstract}

\section{Introduction}

Houses are important places for people to live, study and work. The 'health status' of housing construction directly affects the safety of housing construction and relates to the safety of people's lives and property. Structural health monitoring is an important means to ensure structural safety[1]. It is a very meaningful work to conduct structural health monitoring of housing construction and detect the 'danger signal' of construction with safety warning followed to ensure the safety of housing construction.

Structural Health Monitoring (SHM) refers to the use of non-destructive sensing technology to analyze structural system characteristics, including structural response, to monitor structural damage or degradation[2]. The practice of structural health monitoring of housing construction usually means to form a monitoring network by embedding various sensors in the housing construction, and to conduct real-time monitoring, dynamic management and trend analysis of the structure, so as to provide a scientific basis for the reliable use, timely maintenance and life prediction of housing construction. The purpose of structural health monitoring is to ensure the safety of buildings, so structural health monitoring is also known as 'safety monitoring'.

Safety monitoring includes monitoring in the period of construction and that of use, and the latter is long-term real-time monitoring[3]. Therefore, the workload will undoubtedly be extremely huge, and the required capital investment will be a considerable number if conducting comprehensive safety monitoring. Especially for existing buildings, it can be said to be an impossible task. Therefore, it is necessary to study how to select appropriate monitoring content and monitoring programmes in order to improve the efficiency and effectiveness of structural health monitoring in the circumstance that resources are limited (mainly financial constraints).

\section{Current Status of Old Houses Safety Monitoring}

\subsection{Old Houses and the Safety Status}

According to statistics, China's existing housing construction area has reached to 56 billion square meters approximately, of which a large part of the buildings were built in the early 1980s and 1990s in order to realize the majority of residents' housing dream as soon as possible; some buildings were built earlier. These buildings have a relatively long housing age. There are a series of problems in these buildings, such as low technical standards, nonstandard design and construction, and poor quality of building materials used at that time due to various reasons. Some of them have not been demolished until now, and there are still residents living in these buildings, that are classified as old buildings[4].

According to the provisions of China's 'Unified Standard for Reliability Design of Building Structures' ( GB50068 ) and 'Unified Standard for Civil Building Design'(GB50352), the design life of ordinary housing construction is 50 years, so the buildings built in the 1980 s and 1990s have entered the middle and late life span. With the design life gradually approaching, the health problems of old houses will gradually emerge.

In the long-term operation and maintenance process of old buildings, both the geometric performance degradation of structural materials and the fatigue corrosion of structural components inevitably cause damage to the structure. With the gradual accumulation of

*huangxc45@stu.scu.edu.cn 
damage, it will inevitably affect the safe use of the structure. In addition, due to natural disasters (such as earthquakes and fires) and improper maintenance and use of commercialised buildings, building structure will inevitably produce varying degrees of damage, resulting in damage accumulation and resistance attenuation. Therefore, the safety of old buildings is worth worrying under the accumulation of damage caused by natural aging, natural disasters and improper maintenance.In recent years, media reports of old building safety accidents emerge in endlessly: August 29, 2020, Shanxi Xiangfen County built in 1982 a hotel collapsed[5]; On 28 August 2019, a six-story residential building of Hepingxinju built in 1985 in Luohu District of Shenzhen collapsed[6]; On February 2,2017, a house collapse accident occurred in Dahui Village, Baizhangji Town, Wencheng County, Wenzhou City[7]. On February 26, 2016, a ten-year-old house in Xinqianxiang, Anyuan District, Pingxiang City, Jiangxi Province collapsed partially[8].

Old houses have low reliability and high security risks. In order to ensure the safety of people's lives and property and urban renewal, in the previous years the governments of different regions have taken a costly way to demolish them. However, after the 18th National Congress of the Communist Party of China, China has gradually formed Xi Jinping 's socialist thought with Chinese characteristics for a new era. 'Green water and green mountains are golden mountains and silver mountains', and China will adhere to green development for a long time. China 's old building built in different historical periods, with different characteristics of the times, constitute a specific historical period of cultural symbols, increasingly become the local identity and public memory of the times. In order not to separate the historical context of each place, not to cut off the nostalgia memory of residents, and to implement $\mathrm{Xi}$ Jinping's thought of socialism with Chinese characteristics in the new era and promote green development, China will no longer choose to end old buildings with demolition. Therefore, the old buildings will exist for a long time in the future.

\subsection{Contents of Old House Safety Monitoring}

Old houses have signs before safety accidents. Only timely capture of early warning signals and timely response measures can prevent the occurrence of safety accidents, so as to avoid losses to people's lives and property. Therefore, effective structural health monitoring before safety accidents is an important measure to ensure the safety of old houses.

The damage that brings security risks to old houses can be divided into four categories[9]. First is the overall deformation of the house. If the overall stiffness of the house (especially the foundation stiffness) is particularly large, it is prone to overall tilt when uneven settlement occurs on the foundation of the house or there is a load near the building. A second is the deformation of structural members, such as insufficient thickness of beam and slab, low concrete strength and long-term deformation, which may lead to excessive deflection of beam and slab;
Compression members such as steel, wood, concrete and other materials may also produce excessive overall or local deflection. Next is the cracks and damage of structural components and joints, such as concrete beams in the mid-span or continuous beam bearing negative bending moment section of the tension zone often produce vertical cracks, under the action of shear may occur shearcompression failure cracks, diagonal compression failure cracks or diagonal tensile failure cracks; Finally, the aging, corrosion or decay of building materials, such as wood perishable in wet environment, steel corrosion under oxidation and electrochemical reaction, brick and stone materials will also produce physical and chemical weathering under long-term natural conditions, prestressed concrete shrinkage and creep under long-term load.

In order to continuously grasp the safety dynamics of old houses and provide the basis for the daily maintenance of old houses and the treatment of potential safety hazards, to prevent the safety accidents of old houses and ensure the safety of the houses and the surrounding environment, it is necessary to continuously monitor the structural component damage or damage hidden dangers that may lead to safety accidents of old houses.

Referring to the relevant norms of China[3,10], the contents of safety monitoring during housing use can include deformation and crack monitoring, strain monitoring, environment and effect monitoring. Deformation monitoring can include foundation settlement monitoring, structural vertical and horizontal deformation monitoring ; Environmental and effect monitoring can include wind and wind-induced response monitoring, temperature and humidity monitoring, ground motion and seismic response monitoring, traffic monitoring, erosion monitoring.

\subsection{Research Status of Safety Monitoring of Old Houses}

In the 1950s, structural health monitoring was first used in aerospace[11]. In the $1980 \mathrm{~s}$, structural health monitoring began to be applied in the field of civil engineering[12]. The first application was in the field of bridge engineering, such as the Flintshire Bridge in the UK, the Michigan Street Bridge in the US, the Akashi-Kaikyo Bridge in Japan, the Youngjiong Bridge in South Korea, the Qingma Bridge in Hong Kong, China, the Humen Bridge in Guangdong, and the Runyang Yangtze River Bridge in Jiangsu. In the middle and late 1990s[13], structural health monitoring in the field of housing construction engineering began to be used in many countries, such as the Miyacha Gymnasium in Italy, the National Swimming Center of China, the Lehrter Railway Station in Germany, the East Hangzhou Railway Station in China, the West Beijing Railway Station and the South Kunming Railway Station. However, due to the complexity and cost of structural health monitoring system technology, it is often used in high-rise, super high-rise buildings or large stadiums, railway and highway stations and other public buildings in the field of housing construction engineering. Research on structural health monitoring domestically and 
abroad is more from the technical point of view around the damage identification method, damage index selection, modal parameter identification and practical engineering sensor optimization layout, measuring point layout.

At present, there are few studies on the practical application of structural health monitoring of old houses in China and abroad, and it is still in the exploratory stage. Compared with high-rise buildings, super high-rise buildings and large public buildings, the number of old buildings is large, the size of the building is small, and the property rights are generally privately owned by the residents. To implement structural health monitoring, the cost needs to be funded by the residents, and it is obvious that the cost of structural health monitoring can be used is very limited.

\section{Another section of your paper}

Most residents of old houses are not economically affluent and unable to pay a large amount of money for comprehensive housing safety monitoring. It is therefore essential to study the prioritization of different housing safety monitoring aspects in order to identify more costeffective monitoring programmes. Since the analytic hierarchy process is very practical and effective in dealing with complex decision-making problems, the analytic hierarchy process is selected to establish the optimization model of the safety monitoring scheme of old houses.

\subsection{Introduction of Analytic Hierarchy Process}

Analytic Hierarchy Process ( AHP ) is a system analysis method which combines qualitative and quantitative analysis initiated by Professor T. L. Saaty of the
University of Pittsburgh in the 1970s. The analytic hierarchy process decomposes the elements related to decision-making into different levels. According to the expert judgment, the relative importance of each level of elements is quantitatively expressed, and the value of the relative importance order of all elements in each level is determined by mathematical method. Through the analysis of each level, the analysis of the whole decisionmaking problem is derived[15].

Analytic Hierarchy Process using steps[16] are : (1) Establish hierarchical structure, and determine the various levels of indicators; (2) Compare in pairs with the importance of the same layer elements on a certain criterion in the previous layer, and construct the judgment matrix; (3) Conduct hierarchical single sorting and consistency test, and if the consistency ratio C.R. $\geq 0.10$, it will return to Step (2); (4) Conduct hierarchical total sorting and consistency test. If the consistency ratio C.R. $\geq 0.10$, it will return to Step (2) ; (5) Calculate the synthetic weight of system objectives and sort.

The analytic hierarchy process is clear and easy to operate. By improving the hierarchical structure of the optimization of the old housing safety monitoring scheme, the optimal safety monitoring scheme of the old housing can be scientifically and reasonably selected under the condition of capital constraints.

\subsection{Hierarchical Structure}

In order to optimize the old housing safety monitoring scheme, considering the monitoring cost and housing status as the basis for scheme selection, a hierarchical structure is established as shown in Figure 1.

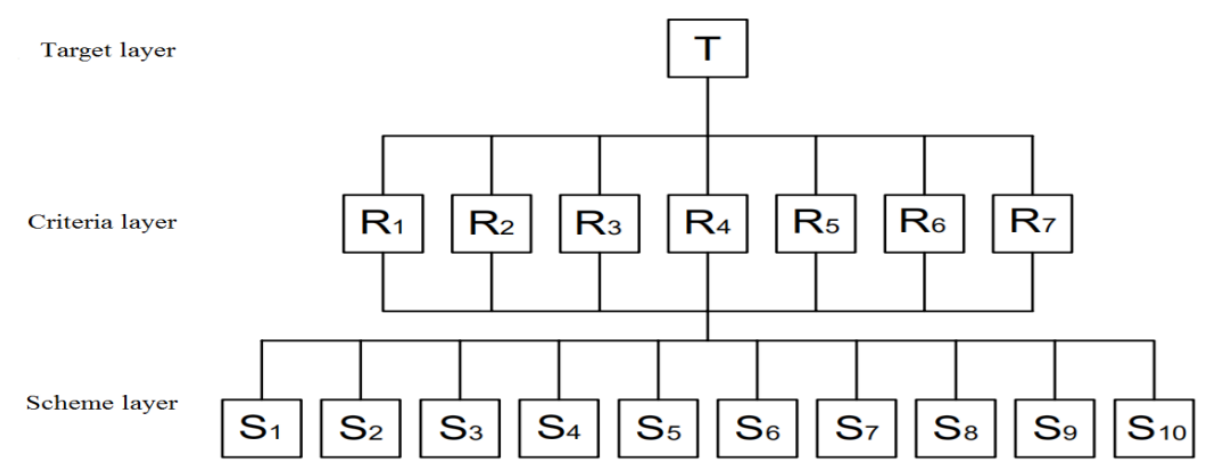

Figure 1. Hierarchical Structure Chart of Old Building Safety Monitoring Scheme Optimization

Target layer: T: Old House Safety Monitoring Scheme Optimization. The goal of this study is to select a safety monitoring scheme that takes into account applicability and economy for old houses.

Criteria layer : $\boldsymbol{R}_{1}$ : monitoring cost. Since the safety monitoring of old houses requires residents' investment, and the residents' economic payment ability in old houses is limited, the monitoring cost must be specially considered. $\boldsymbol{R}_{2}$ : type of structure. China's old houses are mostly brick-concrete structure, bottom frame structure, and a small number of frame structure. Different types of buildings have different damage characteristics, so their safety monitoring contents are different. $\boldsymbol{R}_{3}$ : the length of housing age. Under the same conditions of other factors, the longer the housing is built, as the older the person is, the worse the physical health of the person is, the performance of the housing structure will naturally degenerate, the greater the security risk will be, the higher the urgency of monitoring will be, and the monitoring content will be different accordingly. $\boldsymbol{R}_{4}$ : usage and maintenance. The housing design life, set by China 's national standards GB50068 and GB50352, is based on 'normal design, normal construction, normal use, normal maintenance' conditions. Although in the early stage of reform and opening-up, the laws, regulations and technical standards are not as sound as they are now, they are always under the supervision of the state. 'Normal design and normal construction' are relatively guaranteed, 
but 'normal use and normal maintenance' are difficult to reach the expectation. Residents generally believe that the house is their own, and they can use the house according to their own preferences. The rough use behaviours such as arbitrarily dismantling and changing the wall, cutting the line grooves, large-area cutting and polishing the paint repeatedly, and increasing the load without authorization are common, and the 'normal use' is mostly not guaranteed. House 'normal maintenance' refers to the necessary inspection, protection and maintenance of the house during the use period. For most old buildings, 'normal maintenance' may not exist at all. Therefore, the use and maintenance of housing has a great impact on housing safety, which inevitably affects the content selection of housing safety monitoring. $\boldsymbol{R}_{5}$ : environmental conditions. Adverse environment has a significant impact on the formation of housing damage. If all building materials have the characteristics of thermal expansion and contraction, additional tensile and compressive stress will be produced on the component when thermal expansion and contraction are restricted; $\mathrm{CO}_{2}$ in the air makes concrete carbonized, which leads to the destruction of passive film and the loss of protection of steel bars, resulting in corrosion after the intrusion of water and oxygen; Freeze-thaw cycles will have a destructive impact on building foundations and walls; The buildings near the busy roads are affected by vibration for a long time, and the 'aging' is faster than that of the back streets. Therefore, the environment of old buildings, including temperature, humidity, adjacent traffic, ground rainwater erosion and other conditions have a significant impact on the selection of safety monitoring content. $\boldsymbol{R}_{\boldsymbol{6}}$ : monitoring equipment. Housing structure safety monitoring needs to include the following equipment: sensors, data acquisition equipment, data transmission equipment, data storage and analysis equipment, manual inspection equipment and data early warning equipment. Since China's housing safety monitoring is not yet mature, the choices of the monitoring equipment on the market is limited, and the monitoring equipment is related to the structure type, monitoring project, monitoring method, monitoring period and monitoring system compatibility of monitoring objects, the selection of the content of old housing safety monitoring is closely related to the available monitoring equipment. $\boldsymbol{R}_{7}$ : the maturity of technology. It is not long for China to carry out housing safety monitoring, and the experience is not rich. The maturity of monitoring technology should be considered in the safety monitoring of old houses to improve the accuracy and stability of monitoring.

Scheme layer (alternative monitoring content): $\boldsymbol{S}_{\boldsymbol{I}}$ : foundation settlement monitoring; $\boldsymbol{S}_{2}$ : structure vertical deformation monitoring; $\boldsymbol{S}_{3}$ : horizontal deformation monitoring of structure; $\boldsymbol{S}_{4}$ : temperature monitoring; $\boldsymbol{S}_{5}$ : humidity monitoring; $\boldsymbol{S}_{6}$ : traffic monitoring; $\boldsymbol{S}_{7}$ : wind and wind-induced response monitoring; $\boldsymbol{S}_{\boldsymbol{8}}$ : ground motion and seismic response monitoring; $\boldsymbol{S}_{\boldsymbol{9}}$ : scour monitoring; $S_{10}$ : manual inspection. Real-time quantitative data can be obtained by intelligent instrument monitoring in housing safety monitoring, and quantitative analysis can be carried out. Manual inspection based on visual inspection is more timely and able to play a qualitative and complementary role. It is better to use both intelligent instrument monitoring and manual inspection to supplement and verify each other in the monitoring process. The safety monitoring content of old houses should include 9 items from $\boldsymbol{S}_{\boldsymbol{1}}$ to $\boldsymbol{S}_{\boldsymbol{9}}$. However, considering the limitation of the funds for the safety monitoring of old houses, it is possible to be unable to implement the intelligent monitoring of instruments, in other words, only manual inspection can be implemented. Therefore, the manual inspection is taken as a scheme in the scheme layer.

\subsection{Application of the Optimization Model}

$\mathrm{S}$ Before using this model to optimize the safety monitoring scheme for specific old buildings, the construction age, structural type, change of use conditions, historical repair and transformation, and environment of the buildings are investigated to form a written document. Then, the basic information is provided to the relevant experts, and the judgment matrix is constructed by the experts according to the principle of analytic hierarchy process. Then, the remaining calculation process is carried out by the staff. Finally, the optimization results of the safety monitoring scheme for the old building are obtained, namely the priority order of each monitoring content.

Based on the funding available for the safety monitoring of the old building, the monitoring content is selected according to the priority given.

\section{Conclusion}

AHP model is simple and practical, and it is widely used in various research and application fields. The application of AHP model to the optimization of the safety monitoring scheme of old houses will greatly improve the work efficiency. At the same time, after the establishment of this AHP model, the industry can optimize the content and mechanism of the corresponding housing safety monitoring, ensure less accidents, ensure the safety of people 's lives and property, and ensure the economy and efficiency of old housing safety monitoring.

This model is not the result of an optimal monitoring content, but the priority implementation sequence of each monitoring content. Scheme prioritization is not to encourage the relevant institutions to carry out only part of the monitoring content, but under the realistic conditions of limited funds, the calculated ranking is considered in the housing safety monitoring scheme of relevant projects.

\section{Acknowledgments}

This paper is supported by the innovation and entrepreneurship training program of Sichuan University. The number of this support project is C2021117824. 


\section{References}

1. Achenbach J D. "Structural health monitoringWhat is the prescription?". Mechanics Research Communications, 2009, 36 (2) : 137-142.

2. Li Hongnan, Gao Dongwei, Yi Tinghua. "Advances in Structural Health Monitoring Systems in Civil Engineering". Advances in Mechanics, 2008(02):151-166. (in Chinese)

3. GB50982-2014, Technical code for monitoring of building and bridge structures. (in Chinese)

4. Dai Kaoshan, Luo Mingyan, Chen Yadi,et al. "Assessment and Application of Health Monitoring Technology for Aging Buildings". Structural Engineers, 2017,33(04):90-97. (in Chinese)

5. Information on https://www.sohu.com/a/416116115_215003. (in Chinese)

6. Information on https://www.sohu.com/a/337129090_777433. (in Chinese)

7. Information on http://www.xinhuanet.com/legal/201702/02/c_1120400330.htm. (in Chinese)

8. Information on http://news.xinhuanet.com/local/201602/27/c_1118177617.htm. (in Chinese)

9. Chen Zhiyong, Huang Bo, Pan Jinglong. "Common Damages to Houses and Causes Analysis".Industrial Construction,vol.41， 2011,41(S1):779-784. (in Chinese)

10. T/CECS 685-2020, Technical specification for structural safety dynamic monitoring of buildings. (in Chinese)

11. Pines D, Aktan A E. "Status of structrual health monitoring of long-span bridges in the United States" . Progress in Structural Engineering and Materials, 2002, 4 (4) : 372-380.

12. Chan T H T, Yu L, Tam H Y, et al. "Fiber Bragg grating sensors for structural health monitoring of Tsing Ma bridge:Background and experimental observation".Engineering Structures, 2006,28 (5) : 648-659.

13. Ye Linyuan. Technical Application of Structural Health Monitoring System for Super-tall Buildings. South China University of Technology,2018. (in Chinese)

14. Saaty $\mathrm{T}$ L. The Analytical Hierarchy Process.( McGraw Hill Inc,USA 1980).

15. Wang Lianfen,XU Shubai. Introduction to analytic hierarchy process. (China Renmin University Press,China 1990). (in Chinese)

16. [16] Deng Xue,LI Jiaming,Zeng Haojian,et al. "Research on Computation Methods of AHP Wight Vector and Its Applications". Mathematics in Practice and Theory, 2012,42(07):93-100. (in Chinese) 